\title{
Educational Innovation affects Leadership and Interpersonal Relations in an Experimental School in Northern Greece
}

\author{
Eleni PAPADOPOULOU1', Spyros AVDIMIOTIS²
}

\begin{tabular}{l} 
AR T ICLE INF O \\
\hline Article History: \\
Received \\
07.04.2019Received \\
in revised form \\
13.12.2019 \\
Accepted Available \\
online 01.01.2020 \\
Tarih girmek için buray1 \\
tıklatın.
\end{tabular}

\section{INTRODUCTION}

Innovation is regarded as the transformation of an idea, a product or a process into a product, a service or an improved process which will be available to the market (Becker et al, 2016). According to the Organization for Economic Co-operation and Development (OECD), there are four types of innovation: product innovation, process innovation, marketing innovation and organizational innovation (Oslo, 2005; OECD, 2000). The educational innovation that concerns this study could be characterized as process innovation since it improves the style of teaching linking together more cognitive subjects and altering the teaching orientation (Hallstedt et al, 2013).

(C) IJERE. All rights reserved Keywords: Innovation, motivation, job satisfaction, leadership, interpersonal relations, education.

\begin{abstract}
Even though the educational system in Greece is exceedingly centralized, the pioneering institution of "Experimental Schools" sheds a ray of light. The innovative and researching acts are systematically conducted in experimental schools with the aim to acquire, communicate and disperse knowledge. Based on previous research findings regarding experimental units' hypotheses was developed towards the argument that innovation is directly correlated with (i) leadership (ii) communication, (iii) interpersonal relationships among teaching staff, contributing to a more effective transfer of knowledge and educational investigate the association between the innovation and the leadership style as well as the interpersonal staff relations of the educational unit, the motivation, the work satisfaction and the communication in an experimental school unit. The primary quantitative study was conducted, using a structured questionnaire, in an experimental primary school in Northern Greece. Data acquired were processed using SPSS v20 and AMOS v17 statistical software. In the first stage the process of descriptive statistics and crosstabs analysis was implemented, and in following stages, factor analysis and Structural Equation Modeling was conducted. Results indicated that innovation is strongly interassociated with motivation. Additionally, innovation is positively associated with job satisfaction, interpersonal relations, leadership and communication inside and outside the educational unit. The way the leadership is imposed is changing using innovation procedures and becomes more participative involving the whole educational staff in the process. The research outcomes indicated that through innovation an educational unit obtains openness to the community, resulting in interpersonal relations reinforcement and in transfer of knowledge. All in all, innovation affects the relations and the way people work in an educational unit to the better and it may be alleged that innovation positively alters the profile of the organization.
\end{abstract}


In educational innovation all level educational workers are involved, having the leader in the front who is able to create a dynamic environment where everything changes and is influenced. (Polka \& Kardash, 2013). Research has revealed that educational innovation influences the leadership style. While traditional manager's role was to direct procedures and behaviors, the current role has altered management into more effective administration styles, emphasizing mutual morale and employees' participation, education and abilities development (Mercer et al., 2010). By applying a democratic style, the leader motivates team members to participate in procedures and decision making and this makes them feel active members of the team (Almudara, 2018) and helps them to strengthen their relationships (Lewin et al., 1939). The frame in which the relations develop signifies their quality and enhances them with emotions which can alter under significant circumstances. Interpersonal relations that are cultivated into an educational unit can eagerly promote knowledge as well as reinforce innovation and institution development (Ellet et al, 1997) whilst interpersonal relations are important dexterities for a successful leader and an effective organization (Salovey, 1990). A more modern theory highlights that a working environment which reinforces innovation with the view to boost interactive communication results in personnel's job satisfaction (Chandrasekar, 2011).

The most fertile field to apply educational innovations is the experimental school. Experimental schools are organized to promote innovation and research. According to Gazette, 2011, the main purpose of the experimental schools is: (i) to certify public and high standard quality education for all, (ii) to boost the educational research, (iii) to boost the organization management, assessment and knowledge management, (iv) to function as a training area for under and postgraduate students, (v) to support innovation, creativity and the institution of excellence, (vi) to apply in a pilot- experimental stage syllabus and teaching methods, educational innovation acts and new management forms. From the above it is apparent that innovation is the cornerstone of experimental schools' existence. Given that experimental schools are relatively new in the educational field, little research has been conducted to evaluate its effectiveness and contribution to the innovation inside an educational environment. Educational innovation is a newborn field in Greece with programs which are applied to improve the educational result, given that EU guidelines the countries members to embody innovation into the everyday school life (C.I.D.R.E.E., 1999).

The present study aims to investigate the relations and correlations among innovation, interpersonal relations, leadership, communication, motivation and job satisfaction inside an experimental school.

\section{RESEACH METHOLOGY}

The under research experimental school, situated in a rural area of Northern Greece, has been certified as experimental since 2011 and its continuously trained educational personnel is permanent and assessed every two years through a formal assessment system from the Ministry of Education in Greece.

The contact methodology used was by distributing, fulfilling and collecting of the questionnaires after the school manager was contacted through telephone call and informed about the aim of the study. The number of the distributed questionnaires was 50 whilst 49 valid were collected. The sample is statistically safe as almost all the personnel answered the questionnaires which according to Cronbach's Alpha, the sample is considered representative (more than $90 \%$ of the questionnaires is answered).

The sample is consisted of $85,5 \%$ women and $14,5 \%$ men. There is a variety among the age groups: $34,5 \%$ are between $46-55$ and $36 \%$ are $26-45$ years old. The majority of the personnel (55\%) work in the educational sector for 11-20 years, whilst $20 \%$ of it is fresh to the field with 2-10 years of working experience and $25 \%$ works for more than 20 years. As far as personnel's educational background is concerned the majority of it $(67 \%)$ holds a postgraduate degree and $3 \%$ a doctorate title. All of them are Greek and they work in a Greek public school.

The questionnaire used in the quantitative research, designed by Avdimiotis (2016), is based on motivation and satisfaction theories and techniques. It is consisted of 5 discrete parts to assess motivation, socialization, job satisfaction, leadership and communication inside the team using the five (5) point Likert scale with answers ranging from $1=$ Absolutely Disagree to $5=$ Absolutely Agree. A separate sixth part including demographic questions about gender, age, education and work experience was used.

The factor motivation is consisted of 10 questions which were all answered. A question worth mentioning is: "I am a member of a functional team able to achieve the targets set by the educational organization".

The sector socialization/ interpersonal relations consists of 8 questions all answered. A sample question 
worth mentioning is: "I have close and good interpersonal relations with my colleagues".

The sector job satisfaction consists of 9 questions all answered. It is worth mentioning a sample question: "I receive that the attempt that I make is recognizable".

The sector leadership consists of 6 questions all answered. It is worth mentioning the following question: "The leader shows the ability to concrete relations of good and constructive collaboration.

The sector communication consists of 4 questions all answered and it is worth mentioning the following question: "The communication system in the educational organization is functional".

Statistical analysis was carried out using the Statistical Package for the Social Sciences, SPSS software v20, due to the facilitation, credibility and functionality provided in the outcomes and the Structural Equation Modeling, SEM due to the allowance of association between one or more dependable and one or more latent variables.

\section{Results- Model Evaluation}

Factor analysis: To ascertain that every variable corresponds to only one (1) factor, Principal Components Analysis- PCA using SPSS Statistics was conducted to each variable separately selecting the components creation bigger or equal to one (1) along with Varimax rotation. The Kaiser Meyer Olkin (KMO) test was also used. The variable Job Satisfaction, consisted of 9 questions, was subjected to analysis reaching KMO index at .810 (sig, 0000) and Measure of Sampling Adequacy (MSA) is .703. The analysis derived four factors of satisfaction: (i) subsistence satisfaction, (ii) conditions and workload satisfaction, (iii) suggestions satisfaction and (iv) trust and good interpersonal relations, explaining the variable's $87 \%$. The variable Interpersonal Relations, consisted of 8 questions, was subjected to analysis given the following results: KMO reached .840 (sig, 0000) and Measure of Sampling Adequacy (MSA) is .754. The analysis derived one factor explaining the variable's $68 \%$. The variable Communication, consisted of 4 questions, was subjected to analysis given the following results: KMO is .910 (sig, 0000) and Measure of Sampling Adequacy (MSA) is .873. The analysis derived one factor explaining the variable's $85 \%$. The variable Leadership, consisted of 6 questions, was subjected to analysis given the following results: KMO at .823 (sig, 0000) and Measure of Sampling Adequacy (MSA) is .698. The analysis derived one factor explaining the variable's $85 \%$. The variable Motivation, consisted of 10 questions, was subjected to analysis given the following results: KMO at .610 (sig, 0000) and Measure of Sampling Adequacy (MSA) is .673. The analysis derived three factors: (i) motivation from the work, (ii) cooperation motivation, (iii) recognition motivation, explaining the variable's $60 \%$. The variable Innovation, consisted of 6 questions, was subjected to analysis given the following results: KMO .710 (sig, 0000) and Measure of Sampling Adequacy (MSA) is .689. The analysis derived one factor explaining the variable's $85 \%$.

\section{Confirmatory Factor Analysis}

The confirmatory factor analysis highlighted the factors correlations exported from every variable.

- Innovation actions- Job Satisfaction correlation ,67 (pvalue , 000$)$

- Innovation actions- Communication correlation ,64 (palue ,000)

- Innovation actions- Interpersonal Relations correlation ,63 (palue ,000)

- Innovation actions- Leadership correlation, 76 ( $\left.\mathrm{p}_{\text {value }}, 000\right)$

- Innovation actions- Motivation correlation, 70 (p $\left.p_{\text {value }}, 000\right)$ 
Figure 1. Structural Equation: variables correlation

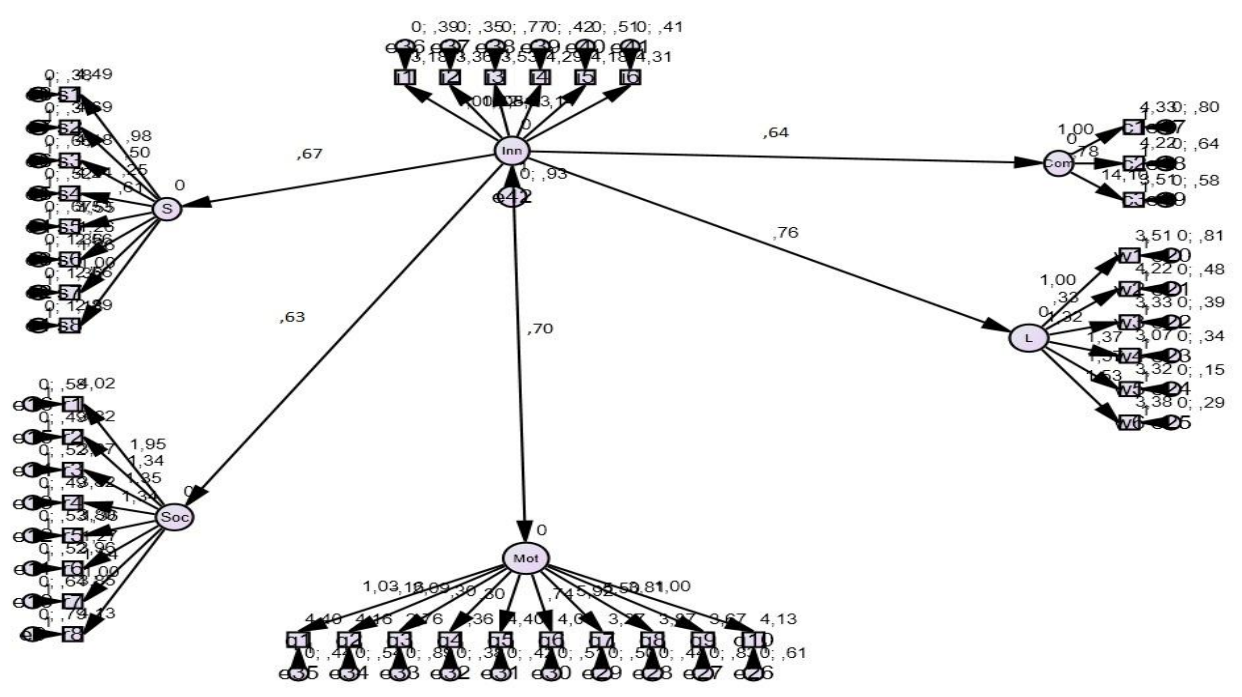

The Confirmatory Factor Analysis (CFA) was completed using AMOS v. 17 software showing the positive correlation among all variables. Innovation had a positive and significant association with the factor Job

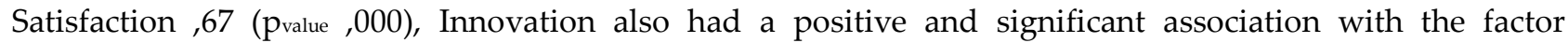
Communication ,64 ( $\left.\mathrm{p}_{\mathrm{value}}, 000\right)$ ), Innovation had a positive and significant association with the factor Interpersonal Relation ,63 ( $p_{\text {value }}, 000$ ), Innovation had a strong association with the factor Leadership ,76 ( $\left.p_{\text {value }}, 000\right)$ and Innovation had a strong association with the factor Motivation indicated correlation ,70 ( pvalue, 000 ). All the observed variables loadings were checked and their loadings were $>0,6$, the CR was $>0,7$ and AVE $>0,5$ whilst the correlation matrixes of the structural variables were $<$ or $=$ to 0,9 . The overall model's fit index CMIN/DFI is acceptable in 1,8 with $p<0,000$. The Root Mean Square Error of Approximation (RMSEA) is 0,775 indicating a satisfactory adjustment level. The Comparative Fit Index (CFI) is 0,883 indicating that the model's adjustment in real facts touches perfection. Apart from the fact that the used measures indicated partial but satisfactory adjustment Bagozzi and Yi (1998) and Dimantopoulos and Siguaw (2000) highlight that under no circumstances are these checks adequate before the inner model's adjustment is examined to ascertain its credibility. Bagozzi and Yi (1998) also, underline that the evaluated relations parameters between the indexes and their factors should be statistically important, so the examining of their credibility and their validity is attainable. $\chi^{2}$ measures the model's adjustment in structural standardizations, and controls the hypothesis that the model is perfectly adjusted (Dimantopoulos and Siguaw, 2000). The path analysis indicated that with degrees of freedom 401, $\chi^{2}$ reached 726,589. The model's adjustment was in significance level of 0,000. During the testing and the model's results the normality levels were observed. Noted that in previous normality testing the non- normality cases were excluded without influencing the total model and its functionality. The parameters estimation was checked with the least squares' method. The model gave $\chi^{2}$ with 402 degrees of freedom $(p=0,000)$. The CMIN/DF fit revealed an acceptable CMIN/DF $=4.846$, according to Bagozzi and Yi (1998), Hair et al (1998), Fornel and Larcker (1981) suggested criteria. The model achieved a RMSEA=0,665, with threshold two sides $90 \%$ confidence interval for the population .068 and a maximum limit .066. Moreover, the model presents price in index CFI $=.783$ and IFI 0.765 , prices that are within the acceptable limits $(>.70)$. The PRATIO $(0.736)$ and PCFI (0 .752) were also within acceptable limits (Mulaik, James, Van Alstine, Bennett, Lind \& Stilwell, 1989). Based on all previous testings all the initial hypotheses are confirmed: 


\begin{tabular}{llll}
\hline $\begin{array}{c}\text { Innovation actions are positively correlated to Job } \\
\text { Satisfaction }\end{array}$ & Confirmed \\
\hline $\begin{array}{c}\text { Innovation actions } \\
\text { Communication }\end{array}$ & are positively correlated to & Confirmed \\
\hline Innovation actions are positively correlated to Leadership & Confirmed \\
\hline Innovation actions are positively correlated to Motivation & Confirmed \\
\hline $\begin{array}{l}\text { Innovation actions are positively correlated to Interpersonal } \\
\text { Relations }\end{array}$ & Confirmed \\
\hline
\end{tabular}

\section{RESULT, DISCUSSION, AND SUGGESTIONS}

The research shows that communication is a dominant instrument on the hands of the leader whilst its efficacious use results in great profits for the team making it functional and effective. The effective leader is called to develop such communication channels that will allow not only his ideas to be heard, but also to listen to his inferiors, to eavesdrop problems, needs as well as to understand better the working climate. Communication can be seen both in personnel meetings where briefing or problem solving takes place and in informal occasions when interaction takes place in organization's recreational areas (Batsis, 1987). Whatever the means is, the meaning always remains the same: to facilitate the information transportation effectively to the interested. In order to communicate a message effectively, the culture and perception of the receiver should be seriously taken into consideration as well as the transmitter's feelings towards the latter, and that is because the information process takes place in the subconscious.

As it is revealed from the study it is crucial for the leader to develop team communication dexterities in order to be accepted from his team so that his ideas could easily be welcomed. Good communication inside the team and its participation in the management reinforces its role and diverts all the obstacles that may arise in the road of development and effectiveness (Torrington, 2009). This can be achieved by making the good relations and the team reinforcement the strongest weapons at his disposal. Educational unit's team members can take responsibilities by participating in the good function of the school unit, adopting a positive attitude towards it, bounding themselves informally for the project completion, reinforcing the team members' self-confidence and self-esteem and making the management cycle stronger and more effective. The team strengthening and the responsibilities distribution facilitate initiatives and work as prerequisites from the organization's successful outcome. This initiative is extremely important for the participatory management, the ultimate management style. When the team feels strongly being part of the management seeks excellence and innovation, understanding deeper the organization's philosophy and its targets, without the need for explanations to be given for every action and process (Lewin et al., 1939).

The research highlights that innovation cannot take place when the interpersonal relations do not exist mostly due to lack of cooperation. Good quality relations collaboration, extroversion and solidarity can be cultivated only through interaction while they are considered valuable for the innovation application (Normore, 2004). Extroversion leads the organization one step forward opening the doors and communicating the professionals' problems and worries leaving behind the ancient perception of the authenticity while simultaneously it facilitates the organization to communicate knowledge. Knowledge leads its way to the educational units and as it is certified from the study, it plays a significant role in the way to innovation. It is an important means for motivation from the aspect that it generates emotional intelligence and has an interactive relation with socialization. It is apparent that it can flourish inside an organization that innovates.

One more crucial factor as seen in this research for the realization of the innovation is motivation wherever it accrues from. Significant and numerous are the examples of motivation from teachers to their students and when this does not happen students' progress is not quite significant (Neves and Conboy, 2001). In this framework, relationships between leaders and educators hinge on motivation to flourish and welcome innovation. Whilst salary satisfaction consists an important motivating factor in entrepreneurship, education professionals indicate to be mobilized through emotional motivation mechanisms and acceptance inside the team rather than materialized goods. According to Maslow's hierarchy of needs (1954) people are 
motivated through their needs which are categorized as following: (a) physiological needs, (b) safety needs, (c) belongingness and love needs, (d) esteem needs, (e) self- actualization needs. In the workplace the motives are of crucial importance for the organization's effectiveness. Feeling accepted and condemned inside a team, employees tend to present higher performance. Emotions constitute significant factors creating a pleasant working environment, whilst positive emotions reignite mental effectiveness, offering the employees the aptitude to understand information better, decide effectively and obtain a flexible way of thinking. As it has become evident from the structural analysis of the present study's data, innovation has a significant positive correlation with leadership given that a participative leadership motivates effectively in its implication. Motivation springs from leader's duties and style, his clear and comprehensible vision and innovation support through which an effective collaboration is obtained (Barker, 2016). His contribution to motivation and development to obtain more scientific knowledge and easily communicate the organization's vision is considered crucial.

The factor analysis results showed that innovation improves job satisfaction making the employee feel acceptable and appreciated inside the organization, maximizing his effectiveness. The workload can be overcome as a barrier to satisfaction and creativity and the application of innovation is able to change the attitude towards work and its conditions. The present study justified that as teachers feel more condemned and satisfied with their work they begin to centralize their profession to their lives and commit themselves to the benefit of the educational unit. Transformational leadership hides behind all these, and together with participate decision management leaders cultivate the most positive attitudes from the teachers as far as their profession is concerned (Whitaker et al, 2013). The leader is the key behind all these, the key that opens all doors in school management. The leader is the element that connects all the other factors mentioned as he is constantly leading the organization to success. Leadership's role is significant as far as the organization's quality, the development of interpersonal relations and the school culture are concerned (Fullan, 2001). This head is the one who will motivate its inferiors for further education, improvement, vision and goals achievement (Barnett, McCormick, 2003). The present research validates the fact that the manager's vision can be conveyed to the educators through communication procedures while innovation is considered the means to obtain positive results in all management spectrums. The multidimensional manager's role is crucial for his inferiors' motivation, whilst his age and his communication dexterities facilitate conception, activation and finally application of the innovation and they also help him become acceptable from the personnel. This acceptance plays a crucial role for innovation's destiny. If his acceptance remains low then whatever idea is promoted from his position is not embraced properly; it is criticized and most of the times rejected without even being seriously examined, putting organization into serious risk (Whitaker et al., 2013). The leader should have a clear vision about the organization's progress and a completed strategy plan to achieve it (Avdimiotis, 2016). Through his interpersonal dexterities he motivates the members of the educational organization to facilitate his vision and helps them understand that they can not only be benefited from the success of this vision but also from the realization attempt. A great leader is the one who facilitates and provides opportunities to people whom he works with to develop themselves and even exceed him in knowledge and abilities ( Papaoikonomou, 2017). From the study it is apparent that the age and the working experience of the staff is of significant importance, optimizing the successful outcome of the applied innovation. Teachers with experience inside the classroom, coming with fresh ideas from universities and open to new procedures and research, experiment more easily, adjust new ideas to their dynamic classroom and dare walk on less uncharted roads. Their recent attendance inside the universities' auditoriums and laboratories has made addicted them to the pursuit of the excellence facilitating them to repudiate the fear of the unknown as they are highly trained to work with scientific research. Considering our under- research sample, a positive perspective was noticed towards innovation, showing them satisfied with their jobs, open to motivation and participation. As proved from the research the most fertile environment for the innovation to flourish is the experimental school whilst innovation and communication as well as the openness to society under the protective shield of the continuous scientific research are their reasons of existence. Free from the tight chains of the centralized educational system experimental schools shed a bright ray of light in the system's perspectives. These schools enjoy the freedom to innovate and work more independently enhancing their personnel with expertized knowledge from the academia as every experimental school is linked with a university faculty in order to promote experimental syllabuses (Gazette, 2011). They stir up the stagnant waters of education inserting new and more dynamic approaches in 
education replacing or developing the traditional educational ways. Enumerating scientific research it becomes apparent that there is poor interest among the scientific community towards this issue and apart from the fact that experimental schools constitute the nucleus of innovation no similar research exists to facilitate comparison and reinforce the argument of experimental schools' importance for the education and society in general. It is imperative for schools to innovate, as proved from the research, replacing the traditional educational ways with more dynamic approaches. Not only the social but also the country's financial prosperity will rely on the citizens' education quality in the future: knowledge dissemination, information uploading and the organizations augmented specialization, demand high capability and training. The current educational organizations are called to be simultaneously effective and efficient. (Cornali, 2012). The innovation application can change the educators' attitude towards their job and its conditions while dynamic relations among the employees are changing improving the extroversion and the interpersonal relations, communication and leadership style. Innovation is positively correlated with job satisfaction, prioritizing the communication inside the team and also towards the leader in order to facilitate innovation effectiveness.

\section{Conclusions}

The conducted study attempted to measure the relations among an educational unit and how these are formed through innovation. The overall outcome is that innovation influences the functionality of the unit in all its aspects due to the special characteristics that the latter should have to facilitate the innovation to succeed. The study revealed that there is strong dynamics between innovation and leadership. A participative style of leadership generates socialization and interpersonal relations inside the team facilitating the innovation's promotion making the leader totally acceptable to his colleagues. Innovation is strongly related to motivation showing that motivation from work, collaboration motivation and recognition motivation complete the chart of a consisted and coherent plan to realize the set goals of the unit. Another strong correlation that the study highlighted is the solid bond between innovation and job satisfaction which is consisted of basic needs satisfaction, suggestions satisfaction and trust in good interpersonal relations, providing room to concrete the argument that satisfaction is not only a personal aspect but carries a social characteristic as well. Innovation and interpersonal relations are correlated, revealing that satisfied colleagues work better under the umbrella of new ideas, develop interpersonal relation and generate emotional intelligence in a totally beneficial way. Last mentioned but not least significant is the important correlation between innovation and communication as the study indicated, giving the strong evidence that innovation is a social phenomenon and can be realized only with the team's work and effort. The more an organization innovates, the better the working environment becomes altering the leadership style to a more participative one. All the above factors sound like musical instruments in a well-tuned orchestra, called innovation, and within the appropriate "opera house", called experimental schools, can do wonders

\section{Limitations and further research}

The researchers' interest about the correlation of innovation with factors such as job satisfaction, motivation, leadership, communication and interpersonal relations inside experimental schools led them to conduct this survey and reach some very hopeful conclusions for the future of the educational innovation and the multiple usefulness in educational management. A bigger, stratified and multicriteria sample would be crucial in order to reach safer and more generalized conclusions. Due to the small number of participants, the outcomes cannot be validated for the whole schools' population. Researchers hope that in the future this survey will inspire academia to take it a step forward by broadening not only the number of schools that will participate in the study but also compare the conclusions with those from typical schools where innovation is not conducted so the extracted outcomes could be generalized for the whole educational system.

\section{REFERENCES}

Albert, D., \& Levine, D. (1988). Teacher satisfaction. Peabody Journal of Education, 65(3), 47-58.

Almudara, S . (2018). Total quality management to reduce cost and to improve quality process in education institution. International Journal of Educational Research Review , 3 (2) , 22-28 . DOI: 10.24331/ijere.391174

Avdimiotis, S. (2016). Tacit knowledge management within hospitality establishments: Revealing the body of the Iceberg. International Journal of Knowledge Management (IJKM), 12(3), 15-29. 
Avdimiotis, S. (2016). We do more than we can tell. perspectives of tacit knowledge transfer in tourism accommodation establishments. Tourismos: An International Multidisciplinary Journal of Tourism. 11, (2), 50-76.

Barker, A. (2016). Improve your communication Skills. New York: Kogan Page.

Barnett, K. \& McCormick, J. (2003). Vision, relationships and teacher motivation: A case study. Journal of Educational Administration. 41, (1), 55-73.

Batsis, T. (1987). Characteristics of excellent principals. Paper presented at the annual meeting of the National Catholic Educational Association, New Orleans, LA.

Beck, L., \& Murphy, J. (1996). The four imperatives of a successful school. Thousand Oaks, CA: Corwin.

Becker, A., Freeman, S., Giesinger Hall, A., Cummins, C., and Yuhnke, B. (2016). NMC/CoSN Horizon Report: 2016 K-12 Edition. Austin, Texas: The New Media Consortium.

Chandrasekar, K. (2011). Workplace environment and its impact organizational performance in public sector organizations. International Journal of Enterprise Computing and Business Systems,1(1), 1-19

C.I.D.R.E.E. (1999). Across the great divides. Interdisciplinary teaching and learningin secondary schools. Athens: Hellenic Educational Institute

Cornali, F. (2012). Effectiveness and efficiency of educational measures. Evaluation Practices, Indicators and Rhetoric,2 (3), 255-260.

Diamantopoulos, A. \& Siguaw, J. (2000). Introducing LISREL. SAGE, London.

Ellett, C. D., Logan, C. S., Claudet, J. G., Loup, K. S., Johnson, B. L., \& Chauvin, S. W. (1997). School learning environment, organizational structures and effectiveness: A synthesis of research in 443 schools. International Journal of Educational Research, 27(4), 273-282. doi:10.1016/s0883-0355(97)90009-4

Fornell, C., Larcker, D.F., (1981). Evaluating structural equation models with unobservable variables and measurement error. Journal of Marketing Research, 18 (1), 39-50.

Fullan, M. (2001). Leading in a culture of change. San Francisco: Jossey-Bass.

Hair, Jr.F., Anderson, R.E., Tatham, R.L. kaı Black, W.C. (1998). Multivariate data analysis. 5th ed. Upper Saddle River, NJ: Prentice Hall

Hallstedt, S., Thomson, A. \& Lindahl, P. (2013). Key elements for implementing a strategic sustainability perspective in the product innovation process. Journal of Cleaner production, 51, 277-288.

Lewin, K., Lippit, R. and White, R.K. (1939). Patterns of aggressive behavior in experimentally created social climates. Journal of Social Psychology, 10, 271-301.

Link, A. \& D. Siegel (2007). Innovation, entrepreneurship, and technological change. Oxford University Press.

Maslow, A. H. (1943). A theory of human motivation. Psychological Review, 50(4), 370-396. doi:10.1037/h0054346

Mercer, J., Baker, B. \& Bird, R. (2010). Human resourse management in education. London and New York: Routledge.

Mulaik, S. A., James, L. R., Van Alstine, J., Bennett, N., Lind, S., \& Stilwell, C. D. (1989). Evaluation of goodness-of-fit indices for structural equation models. Psychological Bulletin, 105(3), 430-445. 
Neves, S. and Conboy, J. (2001). A Stress management Course to prevent teacher distress. International Journal of Educational Management, 15(3),131 - 137.

Normore, A. H. (2004). Lester B. pearson elementary school: First year on a journey with the change process. Journal of Cases in Educational Leadership, 7(35).

OECD (2000). Employment outlook 2000. Paris: OECD

Oslo Manual (2005). Guidelines for collecting and interpreting innovation data. https://el.wikipedia.org/wiki/\%CE\%9A\%CE\%B1\%CE\%B9\%CE\%BD\%CE\%BF\%CF\%84\%CE\%BF\%C E\%BC\%CE\%AF\%CE\%B1

Papaoikonomou, A . (2017). The impact of political socialization on students' behavior: Empirical research in schools of Central Macedonia in Greece. International Journal of Educational Research Review , 2 (2), 1-10 . DOI: $10.24331 /$ ijere. 327468

Polka, W. and Kardash, J. (2013). Managing in the effective change zone to implement a '1-to-1' laptop program in a rural school district. in Ran, B. (Ed.), The Dark Side of Technological Innovation, Information Age Publishing, Charlotte, NC, pp. 323-346.

Salovey, P. \& Mayer, J. (1990). Imagination, cognition and personality. Sage,9, (3), 185-211.

Torrington, D., Hall, L., \& Taylor, S., (2008). Human resource management. 7th ed. Edinburg : Pearson Education Limited.

Whitaker, T., Whitaker, B. \& Lumba, D. (2013). Motvating and inspiring teachers. New york London: Routledge. 